\title{
Simulation of Ni-MH Batteries via an Equivalent Circuit Model for Energy Storage Applications
}

\author{
Ying Zhu, Wenhua H. Zhu, Zenda Davis, and Bruce J. Tatarchuk \\ Center for Microfibrous Materials, Department of Chemical Engineering, Auburn University, 212 Ross Hall, \\ Auburn, AL 36849-5127, USA \\ Correspondence should be addressed to Wenhua H. Zhu; zhuwenh@auburn.edu
}

Received 21 October 2015; Accepted 17 January 2016

Academic Editor: Claudio Fontanesi

Copyright (c) 2016 Ying Zhu et al. This is an open access article distributed under the Creative Commons Attribution License, which permits unrestricted use, distribution, and reproduction in any medium, provided the original work is properly cited.

\begin{abstract}
Impedance measurement was conducted at the entire cell level for studying of the Ni-MH rechargeable batteries. An improved equivalent circuit model considering diffusion process is proposed for simulation of battery impedance data at different charge input levels. The cell capacity decay was diagnosed by analyzing the ohmic resistance, activation resistance, and mass transfer resistance of the Ni-MH cells with degraded capacity. The capacity deterioration of this type, Ni-MH cell, is considered in relation to the change of activation resistance of the nickel positive electrodes. Based on the report and surface analysis obtained from the energy dispersive X-ray spectroscopy, the composition formula of metal-hydride electrodes can be closely documented as the $\mathrm{AB}_{5}$ type alloy and the " $\mathrm{A}$ " elements are recognized as lanthanum ( $\left.\mathrm{La}\right)$ and cerium (Ce). The capacity decay of the Ni-MH cell is potentially initiated due to starved electrolyte for the electrochemical reaction of active materials inside the Ni-MH battery, and the discharge product of $\mathrm{Ni}(\mathrm{OH})_{2}$ at low state-of-charge level is anticipated to have more impeding effects on electrode kinetic process for higher power output and efficient energy delivery.
\end{abstract}

\section{Introduction}

The prosperity of rechargeable Ni-MH and Li-ion batteries rapidly commercializes their application to plug-in hybrid electric vehicles (PHEVs), hybrid electric vehicles (HEVs), and battery electric vehicles (BEVs). Li-ion batteries are in general 50\% lighter in weight and $25 \%-30 \%$ smaller in size [1], making an easier assembly in vehicle, generating more power to boost acceleration, and increasing energy efficiency through on-board battery energy storage via regenerative braking and mechanical-electric energy conversion. A gradual capacity reduction and performance decay are inevitable based on the current knowledge of rechargeable battery technology. It is essential to monitor and control the level of stateof-charge (SoC) in consideration of operating lifetime for the rechargeable batteries. Although the Li-ion battery power packs have remarkable advantages, the on-board energy storage using Ni-MH battery packs is currently powering many of today's hybrid vehicles on the road. This nickelbased metal-hydride battery is lighter than the traditional lead-acid one and approximately delivers twice the power output for the weight as the Pd-acid battery. The accuracy for SoC prediction is a challenge for the requirements of both battery management systems (BMS) and various EV charging infrastructure. Battery impedance is a valid tool to diagnose the cell health conditions and to assist the understanding of electrochemical reaction mechanisms. The limitation for practical applications comes from the difficulties of measurement at load and impedance data interpretation for related physical parameters and electrochemical processes. Electrochemical impedance spectroscopy (EIS) is a valid in situ nondestructive technique for battery evaluation to assess the dynamic responses at loads. It has been experimentally proven by its wide applications to various electrochemical systems, including electrodes-aqueous electrolyte interfaces [2], conducting polymers [3, 4], supercapacitors [5], solar cells [6], fuel cells $[7,8]$, and rechargeable batteries [9-12]. As a whole, it is valuable for further product improvement through deep understanding of the battery deterioration mechanisms during degradation process. The interpretation of impedance data can be achieved by equivalent circuit (EC) simulation and mechanistic analysis. 
Characterizations through EIS impedance for $\mathrm{NiOOH} /$ $\mathrm{Ni}(\mathrm{OH})_{2}$ electrodes $[13,14]$ delivered valuable contributions to the development of nickel-based alkaline rechargeable batteries. The modification of Ni electrodes $[15,16]$ is experienced with the abundant assistance of the EIS technique for performance improvement of Ni-MH batteries. Previously, Kuriyama et al. [17] fully developed a deterioration study of metal-hydride $(\mathrm{MH})$ electrodes with impedance measurement and EC simulation. Recently, researches focused more on characterization of $\mathrm{MH}$ electrodes with different structures [18-20]. At the era of lead-acid (Pb-acid) and nickel cadmium (Ni-Cd) batteries, EIS had been proposed as a promising technique to monitor and determine the SoC levels of full batteries [21]. The study of Bundy et al. [22] was recognized as one of the few thorough impedance studies of full $\mathrm{Ni}-\mathrm{MH}$ battery with attempt to predict the SoC values. Hammouche et al. [23] reported the impedance measurement of a $42 \mathrm{Ah} \mathrm{Ni-MH}$ pack. Half-cell impedance was measured against cell case. Later, Thele et al. [24] followed up the research on large sealed Ni-MH battery pack. Pulse load simulation and hysteresis phenomenon were utilized to validate the Ni-MH battery model. This work provided a valid reference for simulation of the $\mathrm{Ni}-\mathrm{MH}$ systems by impedance analysis. Castro et al. [25] published a mathematical simulation of their lab-made Ni-MH battery based on physicochemical model. Diffusion process was considered in this model, but no fitting curves of impedance spectra were illustrated. Slepski et al. [26] used additional reference electrode to separate impedance measurement of positive and negative electrodes. An EC model of "two time constants" was suggested for the entire battery, but neither simulation process nor fitting curve was reported in detail. In this work, impedance measurement is conducted at the whole cell level for studying of the $\mathrm{Ni}-\mathrm{MH}$ rechargeable batteries. An improved equivalent circuit model considering diffusion process is proposed for battery impedance data simulation at different charge input levels. The model-based impedance analysis is expected to particularly understand the battery performance deterioration at different cell health conditions and assist the mechanism diagnostics for cell capacity degradation.

\section{Experimental}

2.1. Rechargeable Ni-MH Cells for Testing and Evaluation. Two Ni-MH rechargeable batteries were selected for experimental measurements in this work, named as Cell A and Cell $\mathrm{B}$, respectively. The batteries were sealed $\mathrm{D}$-size cylindrical cells with a height of $60 \mathrm{~mm}$ and a diameter of $32 \mathrm{~mm}$. The $\mathrm{Ni}-\mathrm{MH}$ cells were originally purchased from a Radioshack ${ }^{\circledast}$ store (a division of Tandy Corp., Fort Worth, TX) in a brand new condition. The nominal voltage is labeled as $1.2 \mathrm{~V}$ and the nominal cell capacity is marked as $4500 \mathrm{mAh}$ (Radioshack \#23-519). Sealed Ni-MH batteries can generally achieve a cycle life of more than 500 charge-discharge cycles [27] with regular operation. Performance degradation was gradually occurring in the Ni-MH Cell A and Cell B due to years of charge/discharge service cycles and shelf storage. The Arbin Battery Tester (Abts 4.0 with 8 channels) was applied for battery capacity measurement and rate performance evaluation. The cell capacities of the Ni-MH Cell A and Cell B were measured at $3702 \mathrm{mAh}$ and $4362 \mathrm{mAh}$ at a $0.2 \mathrm{C}$ rate after years of services for various laboratory duties and overcharge endurance, respectively. This means the batteries are under different state-of-health $(\mathrm{SoH})$ conditions. In this work, we simply the study by using the nonidentical battery capacity at different cell health status for imitating individual cell position in the real battery power systems after long-term cycling tasks. Impedance measurement is then conducted to study the cell deterioration and capacity degradation mechanisms.

\subsection{Battery Characterization by AC Impedance Spectroscopy.} AC impedance is a type of EIS technique that measures the impedance of electrochemical systems by employing sinusoidal signals as electrical stimulus. To measure cell impedance at a certain capacity level, the specified amount of charge was input to the fully discharged cells at a rate of 0.2 C. As detailed in our previous work [28], the ratio of the charge input to the rated cell capacity (RoC) is defined as

$$
\text { RoC }=\% \frac{\text { Amount of Charge Input }}{\text { Rated Cell Capacity }} .
$$

The value of RoC has some difference in comparison with the value of SoC after the charge input is more than $c a$. $85 \%$ SoC at a $0.2 \mathrm{C}$ rate. When the specified RoC level was reached during the tests, the impedance measurement was applied to the cells under $d c$ current loads. The loaded $d c$ current was $370 \mathrm{~mA}$ for the Ni-MH Cell A and $436 \mathrm{~mA}$ for Cell B. The Gamry impedance monitor and TDI-Dynaload ${ }^{\oplus}$ programmable load were employed to obtain impedance spectra. The frequency swept from $10 \mathrm{kHz}$ down to $0.01 \mathrm{~Hz}$ in each measurement. Impedance data were recorded at a rate of 5 points per decade frequency. When finishing the impedance measurement, the cells were continuously discharged to the cut-off voltage of $1.0 \mathrm{~V}$ at a rate of $0.2 \mathrm{C}$. In other words, the $\mathrm{Ni}-\mathrm{MH}$ cells were fully discharged to a SoC level of $0 \%$ after each impedance measurement. The impedance data at a higher RoC level was measured by repeating this procedure. The proposed equivalent circuit model was utilized to simulate all measured impedance spectra through the software called Gamry Echem Analyst.

The mode of hybrid EIS was selected in this work for Ni-MH cell measurement. The EIS mode was firstly put forward as variable-amplitude Galvanostatic method when studying H-cells with copper/sea water system [29]. The Galvanostatic EIS mode is a perfectly valid technique for impedance data collection but it possibly produces a voltage outside the linear range due to the significant impedance increase. This results in the unacceptable impedance data. The hybrid EIS mode is able to overcome this problem by continually adjusting the applied excitation current during experiment. The electrochemical systems were studied under constant current density. However, the current signal applied to the testing system is regulated in the hybrid EIS mode before measurement of each data point. The signal regulation is able to yield an $a c$ voltage at desired magnitude to ensure 
a pseudolinear behavior, and consequently the ac voltage does not extend beyond the linear range. The validation and accuracy of impedance measurement highly rely on the pseudolinear behavior of electrochemical systems.

During the impedance measurement in this work, a desired voltage perturbation and an estimated impedance magnitude were set before the measurement. The initial current perturbation [30] was calculated by

$$
\Delta I_{1}=\frac{\Delta V}{\left|Z_{\text {est }}\right|},
$$

where $\Delta I_{1}$ was the amplitude of the current perturbation superimposed on the $d c$ load for measurement at the first frequency point. $\Delta V$ was the amplitude of the desired voltage perturbation, chosen as $5 \mathrm{mV}$ for this specific application. The value of $\left|Z_{\text {est }}\right|$ was the magnitude of the system impedance estimated before the measurement. The measured impedance value at this frequency point was then recorded as $Z_{1}$. The current perturbation employed for each following frequency point was calculated by $[29,30]$

$$
\Delta I_{n}=\frac{\Delta V}{\left|Z_{n-1}\right|},
$$

where $\Delta I_{n}$ was the amplitude of the current perturbation used at the $n$th measuring point and $\left|Z_{n-1}\right|$ was the magnitude of the system impedance measured at the $(n-1)$ th point.

2.3. Electrode Materials Composition by Energy Dispersive XRay Spectroscopy. One of this type of nickel metal-hydride cell was cut and broken down to get small amount of samples from the negative electrodes for surface analysis. The electrode composition was analyzed by energy dispersive Xray spectroscopy (EDX or EDS). The EDX surface technique is a bulk analytical technique used to qualitatively and quantitatively detect element composition. It is able to probe 3-4 $\mu \mathrm{m}$ below the surface of the powder and has a sensitivity of about $1000 \mathrm{ppm}$ for elements from beryllium (Be) with atomic number 4 to uranium (U) with atomic number 92 . The electrode samples were powdered and pressed into doublesided $\mathrm{C}$ tape on the EDX specimen mount. The composition of metal alloy used for the negative electrodes was detected by identifying the metal elements and their percentage.

\section{Results and Discussion}

3.1. Electrode Compositions. The formulas of metal-hydride alloys used for the negative electrode of the $\mathrm{Ni}-\mathrm{MH}$ batteries basically follow the disordered $A_{5}$ type, $A_{2} B_{7}$ type, or disordered $\mathrm{AB}_{2}$ type [31]. The typical elements on " $\mathrm{A}$ " sites and " $B$ " sites are different in various alloy types; however, " $A$ " generally refers to rare earth mixture and " $\mathrm{B}$ " refers to transition metals. According to Ovshinsky's valuable work on the $\mathrm{MH}$ negative electrodes for $\mathrm{Ni}-\mathrm{MH}$ batteries [32], the disordered $\mathrm{AB}_{5}$-type mischmetal (Mm) alloy [18-20] has been developed to be available for the most commercial use performing better cycle ability than other alloy structures. In this work, EDX reported that the electrode samples

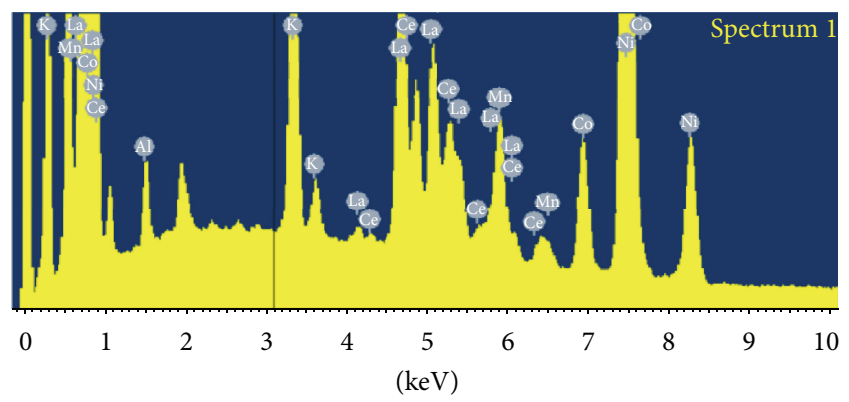

Full scale 4918 cts cursor: 3.086 (1311 cts)

FIGURE 1: EDX spectrum for a sample of the $\mathrm{Ni}-\mathrm{MH}$ negative electrode. The sample approximately matches the $\mathrm{AB}_{5}$-type alloy with the primary components including nickel (B) and lanthanum (A) elements, based on the surface analysis tool.

approximately follow the atomic ratio of $\mathrm{AB}_{5}$ as shown in Figure 1. The "A" type elements include lanthanum (La) and cerium (Ce). The "B" type elements include nickel (Ni), cobalt (Co), aluminum (Al), and manganese (Mn) with the primary component of Ni. Small amount of potassium (K) was also detected in the analytic process. This results from the use of $\mathrm{KOH}$ electrolyte during assembling of the Ni-MH cell. The element of $\mathrm{Mn}$ is able to adjust the metal-hydrogen bond strength [32], and the existence of $\mathrm{Al}$ and Co significantly promoted electrode kinetics [31, 32]. Based on the EDX report and analysis, the formula of this $\mathrm{AB}_{5}$-type hydride alloy can be roughly expressed as $\left(\mathrm{La}_{9.70} \mathrm{Ce}_{4.39}\right)\left(\mathrm{Ni}_{60.75} \mathrm{Co}_{6.66} \mathrm{Al}_{3.59} \mathrm{Mn}_{4.45}\right)$, according to Fetcenko et al.s work [31] on the composition of metal-hydride alloys.

3.2. Impedance Spectra and Equivalent Circuit Simulation. The Ni-MH cells became aged states after various operating tasks, and the cell capacities were measured as $3702 \mathrm{mAh}$ and $4362 \mathrm{mAh}$, less than the nominal capacity of $4500 \mathrm{mAh}$ as specified by the manufacturer. The capacity reduction reflects cell degradation during numerous cycling loads at ambient shelf storage conditions. This represents the state-ofhealth $(\mathrm{SoH})$ change for individual cells. Impedance spectra of the Ni-MH cells measured at different capacity levels are illustrated in the same Nyquist plots as shown in Figure 2. The impedance arcs of both cells at higher frequency region have the arc shapes similar to depressed semicircles. Comparing the magnitudes of these impedance arcs at $X$ direction and $Y$ direction, these "semicircles" are depressed to a large extent. A change of curvature can be observed clearly at higher frequency region from the impedance spectra of the $\mathrm{Ni}-\mathrm{MH}$ cell (Cell A), which implies the possibility of two overlapped impedance arcs. One straight tail dominates the behavior of cell impedance at lower frequency region of both cells at all SoC levels. Despite the similar shape of impedance spectra, the total impedance of the Ni-MH Cell B is slightly larger than the value of Cell A. The impedance of Cell B also executes larger changes with increasing the charge input than the value of Cell A. The altered magnitude and behavior of impedance 


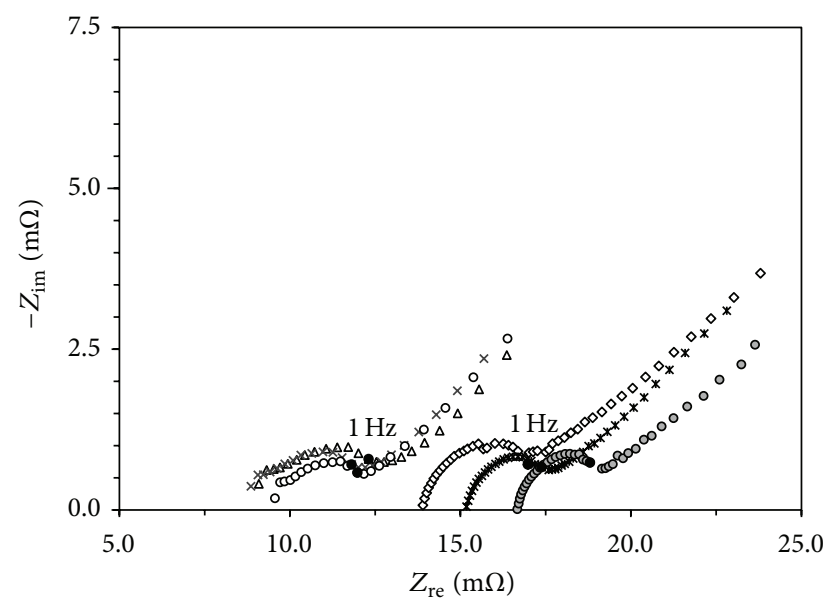

$\begin{array}{lll}\Delta \text { Ni-MH Cell A RoC 40\% } & \diamond \text { Ni-MH Cell B RoC } 40 \% \\ \times \text { Ni-MH Cell A RoC 60\% } & * \text { Ni-MH Cell B RoC 60\% } \\ \circ \text { Ni-MH Cell A RoC 100\% } & \circ \text { Ni-MH Cell B RoC 100\% }\end{array}$

FIgURE 2: Impedance spectra of the Ni-MH Cell A and Cell B measured after charging to the RoC levels of $40 \%, 60 \%$, and $100 \%$. The impedance data measured at the frequency of $1 \mathrm{~Hz}$ are highlighted in the plot $(\bullet)$.

spectra illustrate different amount of capacity decay in two $\mathrm{Ni}-\mathrm{MH}$ rechargeable cells.

A typical Randles circuit as shown in Figure 3(a) consists of one ohmic resistance, $R_{\Omega}$, one parallel $\left(C_{\mathrm{dl}} R_{\mathrm{ct}}\right)$ subcircuit behaving as a semicircle in Nyquist plot, and one Warburg element (symbolized by $W$ ) behaving as a unit slope line at the lowest frequency region [33]. This model considers faradaic impedance contributed by both kinetic reaction processes and diffusion processes. Since the depressed semicircles were observed from the impedance spectra of the Ni-MH cells, a modification to Randles circuit is necessary to be considered for the circuit model expansion and improvement.

One explanation to the depression is the existence of nonideal behaviors, usually caused by the surface roughness and varying thickness of electrodes, unevenly distributed current, and nonhomogeneous reaction rate. A generalized element, constant phase element (CPE, symbolized by $Q$ ), can be used to replace ideal physical elements in the case of nonideal behaviors. The phase angle of CPE remains constant through all the frequency range [34]. The impedance of a CPE [33] can be written as

$$
Z_{\mathrm{Q}}=A(j \omega)^{-n}=\frac{1}{Y_{0}(j \omega)^{n}}
$$

The exponential number $n$ reflects the degree of nonideality. When the value of $n$ in (4) equals $1,0,-1$, and 0.5 , this equation turns out to be the expression of pure capacitor $C$, pure resistor $R$, pure inductor $L$, and Warburg element, respectively. To simulate the nonideal capacitive behavior, the value of $n$ needs to be limited between 0.8 and 1.0 [33]. With this valid restriction, one $\left(Q_{\mathrm{dl}} R_{\mathrm{ct}}\right)$ failed to simulate the impedance arcs at higher frequency region. In this case, the overlap of two semicircles is preferred to explain the large extent depression. One more parallel $(C R)$ subcircuit
(Figure 3(b)) was added into a series with the Randles circuit to derive the ideal equivalent circuit model (Figure 3(c)) for studying of the full Ni-MH cells. To improve the fitness of the equivalent circuit model to the experimental data, nonideal processes are essential to be considered for the Ni-MH cells. In this work, the ideal equivalent circuit model in Figure 3(c) was further modified to the nonideal equivalent circuit model as shown in Figure 4. It is an improved equivalent circuit model in this work proposed for the following simulation efforts. Three CPEs were applied to replace two ideal capacitors and one Warburg element for nonideal capacitive behaviors and nonideal diffusion behavior. The simulation fitness of this nonideal improved model to the experimental data measured in this work is illustrated as shown in Figure 5. The impedance spectrum measured from the Ni-MH cell at a capacity level of $c a$. 30\% SoC (dots) was plotted to detail the fitness of simulation curve (solid line). The pure resistor $R_{\Omega}$ refers to the smaller intercept of impedance spectra in real axis. Two parallel subcircuits $\left(Q_{\mathrm{dl}, 1} R_{\mathrm{ct}, 1}\right.$ and $\left.Q_{\mathrm{dl}, 2} R_{\mathrm{ct}, 2}\right)$ are applied to simulate two overlapping impedance arcs in higher frequency range. For nonideal capacitive behavior, the exponential numbers of $Q_{\mathrm{dl}, 1}$ and $Q_{\mathrm{dl}, 2}$ are expected to stay between 0.8 and 1.0. The element $Q_{\text {diff }}$ simulates the straight lines in the low frequency range for the nonideal Warburg behavior with an exponential number slightly less than 0.5. The simulation result from the fitting curves presents good consistency with measurement data.

Kuriyama et al. [17] proposed an equivalent circuit model of "four time constants" for the MH electrodes. The model consisted of three $(C R)$ parallel circuits and one Warburg element. The fitting values of model elements were utilized to study the deterioration mechanism of electrodes without showing the fitting curves. However, equivalent circuit models having less time constants were preferred to avoid redundancy. An equivalent circuit model with diffusion element of "three time constants" [20] was developed by Tliha et al. to simulate their $\mathrm{AB}_{5}$-type $\mathrm{MH}$ electrodes at altered SoC levels. The mature research on $\mathrm{NiOOH} / \mathrm{Ni}(\mathrm{OH})_{2}$ electrodes confirmed that an equivalent circuit model consisted of one (CR) parallel circuit and one diffusion circuit [13]/diffusion element [35] was capable of providing excellent electrode simulation. Slepski et al. [26] suggested an equivalent circuit model of "one time constant" for their positive electrode and an equivalent circuit model of "two time constants" for their negative electrode. However, the suggested equivalent circuit model only had two time constants. No diffusion element was considered either in electrode models or in full battery model. In this work, the proposed nonideal equivalent circuit model has three time constants with consideration of diffusion processes. The impedance spectra of positive and negative electrode overlapped to some extent at higher frequency region; however, two $(Q R)$ subcircuits were preferred to distinguish contributions from each electrode.

The simulation results of the Ni-MH Cell A and Cell $\mathrm{B}$ at different RoC levels are shown in Figures 6 and 7. In higher frequency range, the two parallel $(Q R)$ circuits simulate the measured impedance spectra quite well under all cell status. However, the fitting curves gradually deviate from the impedance data when the frequency decreases to 


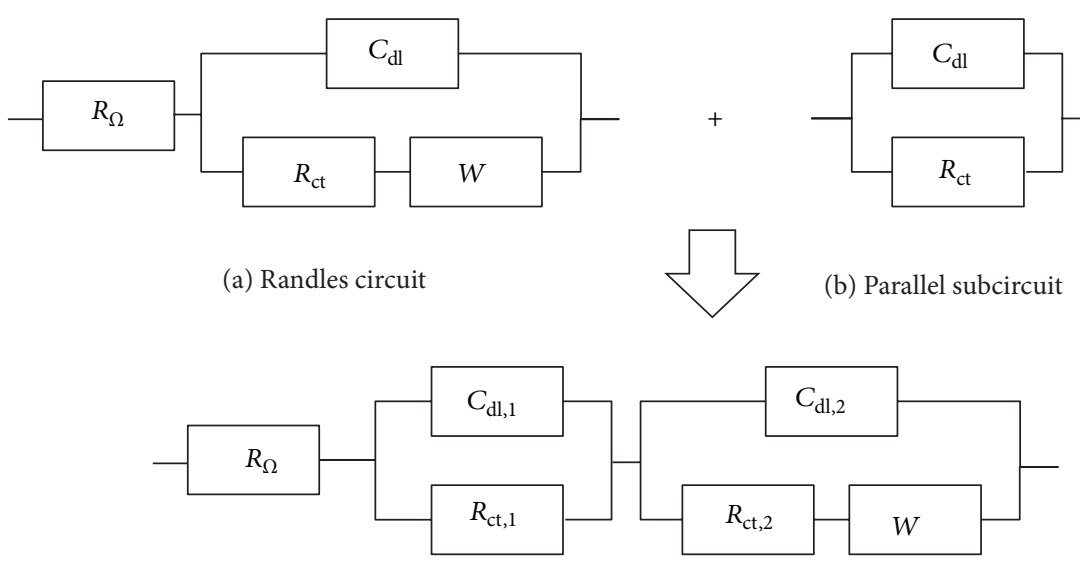

(c) Typical ideal equivalent circuit model for a Ni-MH cell

FIgure 3: (a) Randles circuit. (b) Paralleled (CR) subcircuit. (c) Typical ideal equivalent circuit model for a full Ni-MH cell.

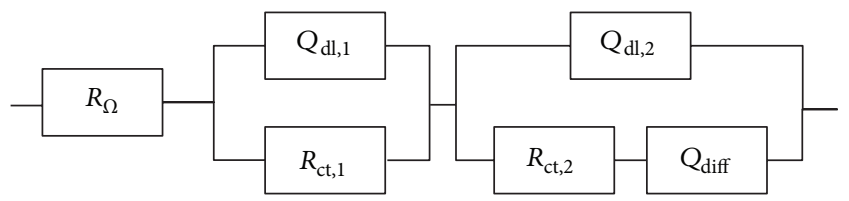

FIGURE 4: An improved nonideal equivalent circuit model proposed for impedance simulation of the Ni-MH cells.

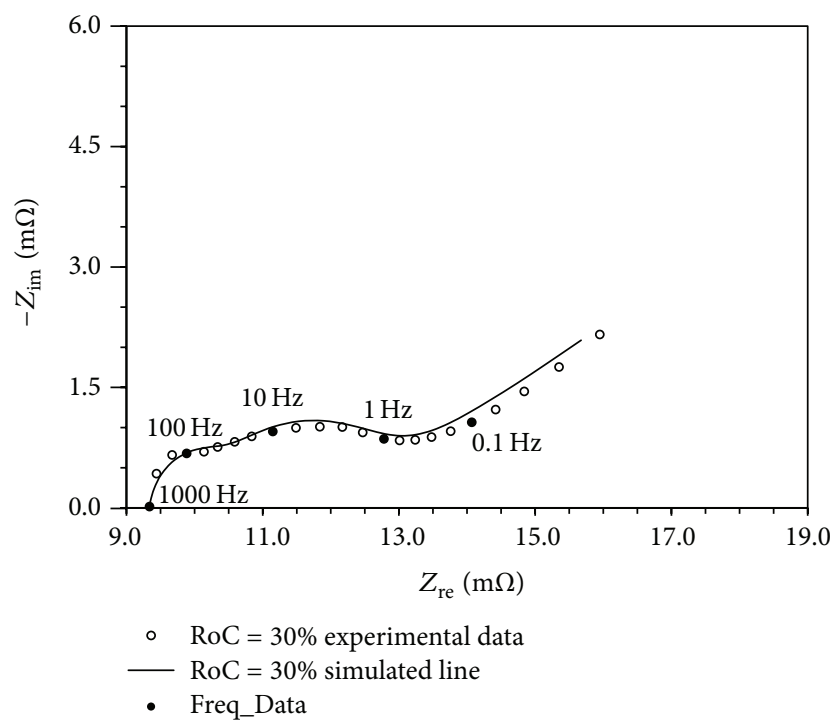

Figure 5: Impedance spectra measured from the Ni-MH cell (Cell A) at a $30 \% \operatorname{RoC}(c a .30 \%$ SoC) level, simulated by the improved equivalent circuit model.

lower than $1 \mathrm{~Hz}$. This deviation becomes more significant at higher charge input levels, especially at $100 \%$ RoC level. Mathematical models likely implement better simulation in this frequency region than semiempirical EC models [25].
Other impedance studies of full Ni-MH cells [22, 23, 26] paid more attention to measurement data and SoC studies. Valoen et al. [36] reported an improvement of simulation at low frequency region by considering hydrogen evolution process; however, this work was done merely for $\mathrm{MH}$ electrodes but not for full Ni-MH cells. As a whole, the simulation curves are basically identical with the measured experimental data.

3.3. Interpretation for Equivalent Circuit Elements. The understanding of cell mechanisms can be obtained through equivalent circuit simulation in addition to proper interpretation for physical elements and electrochemical processes. The electrolyte of $\mathrm{Ni}-\mathrm{MH}$ rechargeable batteries is usually a concentrated potassium hydroxide $(\mathrm{KOH})$ solution. The whole discharge process [27] can be described by the following electrochemical reaction as

$$
\begin{array}{ll}
\mathrm{NiOOH}+\mathrm{MH} \stackrel{\text { discharge }}{\longrightarrow} \mathrm{Ni}(\mathrm{OH})_{2}+\mathrm{M} & \\
& E_{\text {cell }}^{0}=1.35 \mathrm{~V}
\end{array}
$$

The reactant of nickel oxyhydroxide $(\mathrm{NiOOH})$ refers to the active material of positive electrodes. Hydrogen is absorbed into metal alloys during the cell charge process and the reactant of $\mathrm{MH}$ refers to the metal hydride alloy at the negative electrodes after charging. The overall reaction of the charging process is simply the reversing process of (5). However, Karden et al. [37] demonstrated that the electrode kinetics is an asymmetric process during charge and discharge for a $12 \mathrm{~V} \mathrm{~Pb}$-acid battery. Batteries potentially undertake different impedance spectra during charging process in comparison to discharging process under the same operating condition. The mechanisms discussed below for the Ni-MH cells are for better understanding of the discharging processes at different RoC levels. 


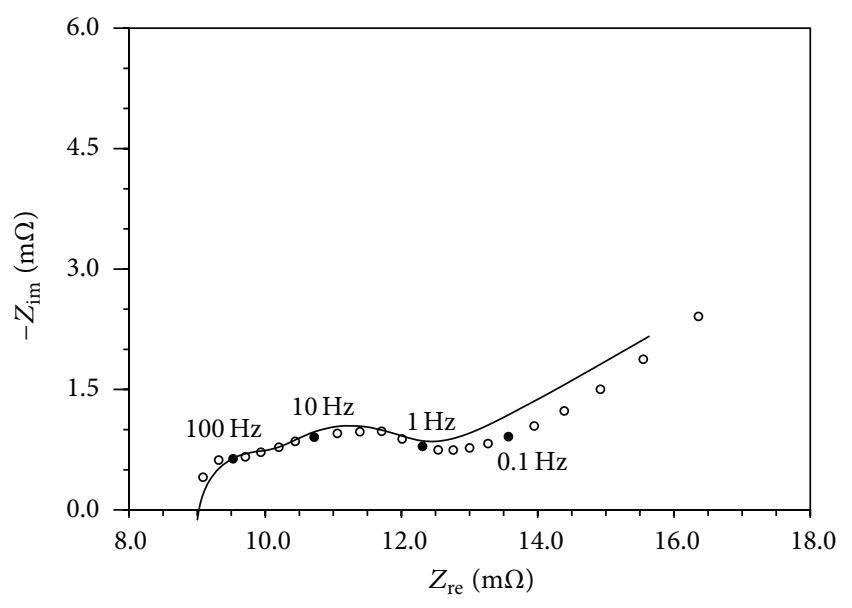

- $\mathrm{RoC}=40 \%$

(a)

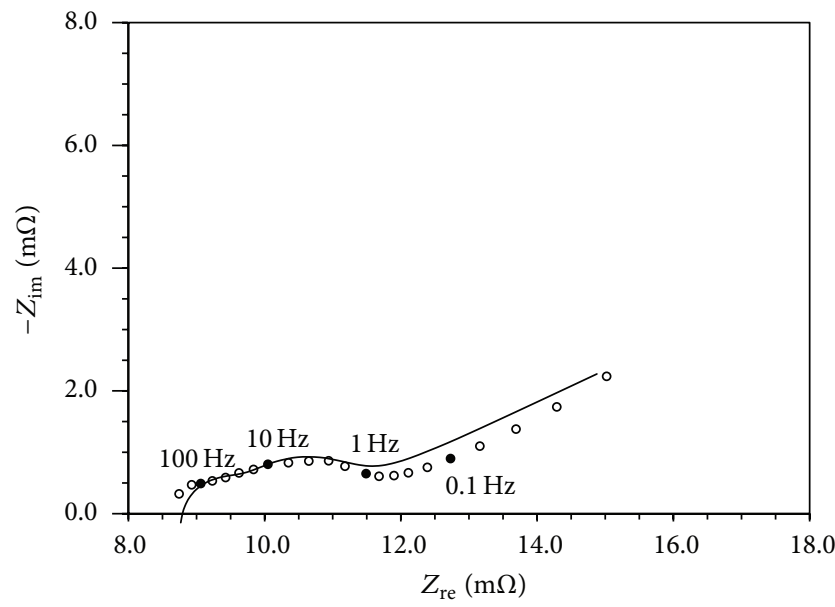

- $\mathrm{RoC}=85 \%$

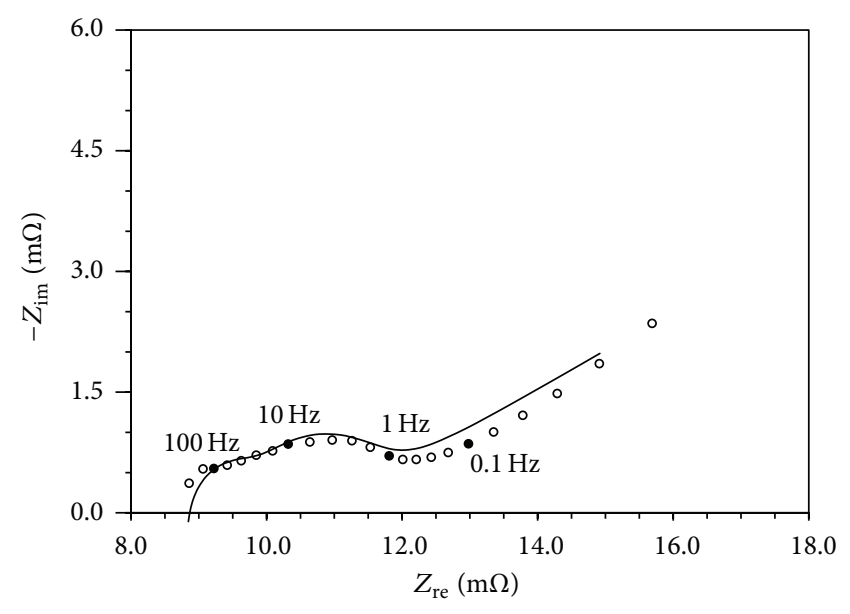

。 $\mathrm{RoC}=60 \%$

(b)

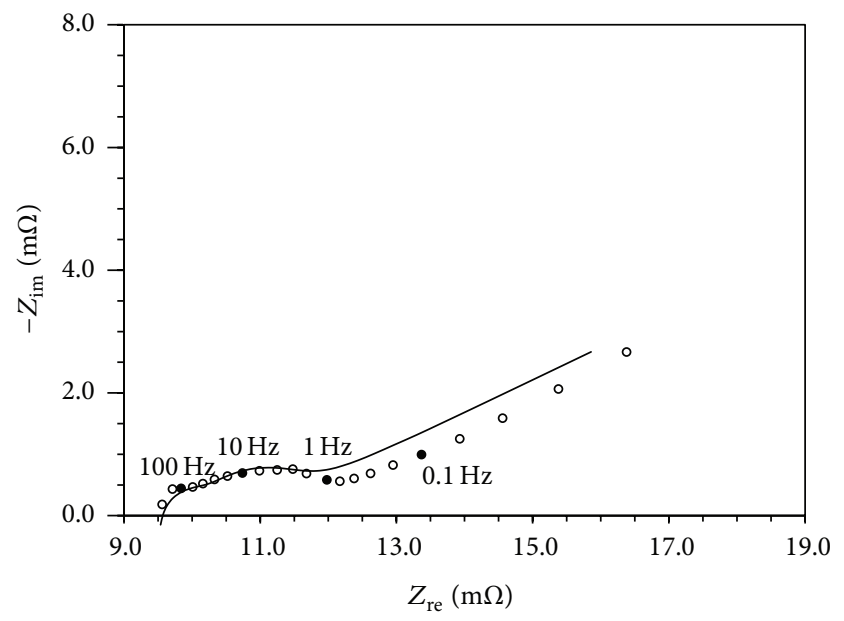

- $\mathrm{RoC}=100 \%$

(c)

(d)

FIGURE 6: Impedance spectra measured from the Ni-MH cell (Cell A) at different RoC levels with fitting curves simulated from the improved equivalent circuit model.

3.3.1. Mechanism on Negative Electrodes. The half-cell process on the negative electrode is called the dehydriding reaction [38]. It can be expressed as follows:

(a) Hydrogen atoms adsorbed in metal alloy transfer from bulk sites to surface sites. These are metal alloy sites at the interface of electrode and electrolyte, described as

$$
\mathrm{M}_{\mathrm{B}} \cdots \mathrm{H}_{\mathrm{ad}}+\mathrm{M}_{\mathrm{S}} \longrightarrow \mathrm{M}_{\mathrm{S}} \cdots \mathrm{H}_{\mathrm{ad}}+\mathrm{M}_{\mathrm{B}}
$$

where $\mathrm{H}_{\mathrm{ad}}$ refers to the hydrogen atom adsorbed in the metal alloy; $M_{S}$ and $M_{B}$ refer to the empty sites of metal alloy on surface and in bulk, respectively. Vitanen [39] explained this process as hydrogen released from the hydride phase to form adsorbed hydrogen atoms.

(b) Hydrogen oxidation reaction (HOR) at the electrode/electrolyte interface is a charge transfer step coupled by the diffusion process of hydroxide ions from bulk electrolyte to the electrode/electrolyte interface. It is represented by

$$
\begin{gathered}
\mathrm{OH}_{\mathrm{B}}{ }^{-} \longrightarrow \mathrm{OH}_{\mathrm{S}}{ }^{-} \\
\mathrm{M}_{\mathrm{S}} \cdots \mathrm{H}_{\mathrm{ad}, \mathrm{S}}+\mathrm{OH}_{\mathrm{S}}{ }^{-} \longrightarrow \mathrm{M}_{\mathrm{S}}+\mathrm{H}_{2} \mathrm{O}_{\mathrm{S}}+\mathrm{e}^{-}
\end{gathered}
$$

where $\mathrm{OH}_{\mathrm{B}}{ }^{-}$and $\mathrm{OH}_{\mathrm{S}}{ }^{-}$refer to the hydroxide ions in the bulk of electrolyte and at the interface of electrode/electrolyte, respectively; $\mathrm{H}_{2} \mathrm{O}_{\mathrm{S}}$ is water atoms produced by the HOR process at the electrode/electrolyte interface.

(c) Transport of water molecules away from electrode/electrolyte interface to bulk electrolyte can be expressed with the following reaction:

$$
\mathrm{H}_{2} \mathrm{O}_{\mathrm{S}} \longrightarrow \mathrm{H}_{2} \mathrm{O}_{\mathrm{B}}
$$

where $\mathrm{H}_{2} \mathrm{O}_{\mathrm{B}}$ is water molecules in bulk electrolyte. 


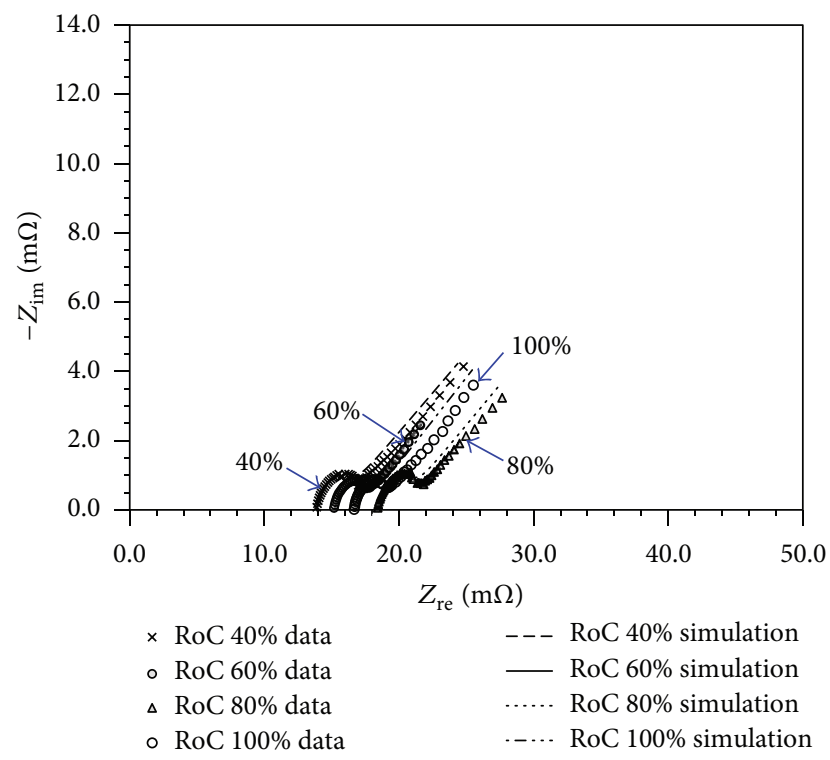

FIGURE 7: Impedance spectra measured from the Ni-MH cell (Cell B) at different RoC levels with fitting curves simulated from the improved equivalent circuit model.

The rate-limiting step on the negative electrode is the one-electron transfer kinetic process (see (8)) when there are sufficient hydrogen atoms adsorbed in the metal alloy sites on electrode surface. Diffusion of hydrogen atoms from bulk electrode to surface sites (see (6)) is a semiinfinite diffusion process featured by Warburg behavior at low frequency. This process does not have significant effect on cell impedance under common conditions $[18,38]$ but will become the rate-limiting process at low temperature [40] due to decrease of diffusion coefficient. The mass transfer process of hydroxide ions (see (7)) from bulk electrolyte to electrolyte/electrode interface is a porous bounded diffusion process. Its impedance effect can be negligible under general conditions but becomes significant under a large $d c$ current load. The rate of hydroxide ion diffusion process lags behind the electrode kinetics at large current loads. The transfer process of water molecules (see (9)) can be neglected when compared to other processes, because the hydroxide ion concentration in electrolyte is assumed to be large enough [38] and globally constant during battery operation [23].

\subsubsection{Mechanism on Positive Electrodes. Zimmerman and} Effa [14] proposed a mechanism for the discharge process of $\mathrm{NiOOH} / \mathrm{Ni}(\mathrm{OH})_{2}$ electrodes. Following this recommended mechanism, the step-by-step reaction can be summarized as follows:

(a) Transport process of water molecules from bulk electrolyte to the interface of electrolyte and electrode, followed by the formation of proton at catalytic site at the interface, is described by the following reactions:

$$
\begin{aligned}
& \mathrm{H}_{2} \mathrm{O}_{\mathrm{B}} \longrightarrow \mathrm{H}_{2} \mathrm{O}_{\mathrm{S}} \\
& \mathrm{H}_{2} \mathrm{O}_{\mathrm{S}} \longrightarrow \mathrm{OH}_{\mathrm{S}}{ }^{-}+\mathrm{H}_{\mathrm{S}}{ }^{+}
\end{aligned}
$$

(b) Transport process of hydroxide ions from the interface back to the electrolyte bulk is written as

$$
\mathrm{OH}_{\mathrm{S}}{ }^{-} \longrightarrow \mathrm{OH}_{\mathrm{B}}^{-}
$$

(c) Electrode reduction reaction of $\mathrm{NiOOH}$ active material, which is a charge transfer process coupled by the diffusion process of proton from the surface site to the charge transfer site in the electrode bulk, is expressed with the following reaction steps:

$$
\begin{gathered}
\mathrm{H}_{\mathrm{S}}^{+} \longrightarrow \mathrm{H}_{\mathrm{B}}{ }^{+} \\
\mathrm{NiOOH}+\mathrm{H}_{\mathrm{B}}^{+}+\mathrm{e}^{-} \longrightarrow \mathrm{Ni}(\mathrm{OH})_{2}
\end{gathered}
$$

The processes on positive electrodes are different from what is discussed above for the negative electrodes. Diffusion process is considered as the rate-limiting step. Its effect on $\mathrm{NiOOH} / \mathrm{Ni}(\mathrm{OH})_{2}$ electrode can be observed under general battery operating conditions [14]. This means that the charge transfer process expressed as (14) is not the rate-limiting process. And the diffusion process of proton in positive electrode (see (13)) is considered as the rate-limiting step under normal discharge process. The impedance of proton diffusion process can be applied to simulate the Warburg behavior.

3.3.3. Full Battery Impedance. The impedance arcs of semiinfinite diffusion processes were observed from impedance spectra of both $\mathrm{MH}$ electrodes [17-20] and $\mathrm{NiOOH} / \mathrm{Ni}(\mathrm{OH})_{2}$ electrode studies [13, 15, 16, 35]. However, only one Warburg behavior arc was observed at low frequency region in this work. Thus, the difficulty of interpretation lies in the diffusion process. Karden et al. [37] measured the half-cell impedance separately and compared the sum of the half-cell impedance to the total cell impedance. The comparison clearly illustrated that the negative electrode impedance dominated higher frequency region and the positive electrode contributed to the diffusion impedance in lower frequency region. Hammouche et al. [23] also reported that the nickel hydroxide electrode contributed the diffusion impedance to the full cell under normal discharge conditions. Based on the discussion of halfcell mechanism in the previous section, the diffusion element $Q_{\text {diff }}$ simulates the rate-limiting diffusion process of positive electrode. It is explained as the solid-state diffusion process of proton in nickel hydroxide electrode expressed as (13). The parallel subcircuit $\left(Q_{2, \mathrm{dl}} R_{2, \mathrm{ct}}\right)$, connecting to the diffusion element, simulates the charge transfer process occurring on the electrolyte/positive electrode interface coupling with the reduction reaction of the active material $\mathrm{NiOOH}$ (see (14)). And the parallel subcircuit $\left(Q_{1, \mathrm{dl}} R_{1, \mathrm{ct}}\right)$ is ascribed to the one-electron transfer process of HOR occurring on the surface of the negative electrode. The pure resistor $R_{\Omega}$, connecting in series to other equivalent circuit elements, simulates the ohmic resistance. It consists of the resistance of cell components (electrodes, electrolyte, and conducting substrates) and resistance introduced by contact and connection. 
3.4. Changes of Ohmic and Charge Transfer Resistances. The correlation between RoC and SoC was studied on the Ni-MH cell (Cell B) [28]. When certain amount of charge input was applied to Cell B, its value of RoC was calculated based on the amount of charge. The SoC level was determined when Cell B was discharged to $1.00 \mathrm{~V}$ cut-off voltage at a $0.2 \mathrm{C}$ rate. Based on the test and calculation results, the values of RoC are identical to the SoC parameter when the capacity level is below $c a$. $85 \%$ SoC. As the value of RoC continues to linearly increase with the amount of charge input, the rate of the SoC increase gradually slows down. The values of SoC deviate from RoC at a higher capacity level, but the difference starts at the beginning with a small magnitude. The reason is that the side reaction of oxygen reduction reaction (ORR) which occurred on the positive electrode (see (15)) competes for the amount of charge input. To protect $\mathrm{Ni}-\mathrm{MH}$ batteries under the overcharge condition, the capacity of negative electrodes is usually designed as 1.5 to 2 times that of positive electrodes [27]. After evolving on the positive electrode, oxygen diffuses through the separators with unsaturated electrolyte and reaches the negative electrode to recombine with water molecules (see (16)). The side reactions on both electrodes during overcharge [27] can be expressed as follows:

Overcharge at positive electrodes:

$$
4 \mathrm{OH}^{-} \longrightarrow 2 \mathrm{H}_{2} \mathrm{O}+\mathrm{O}_{2}+4 \mathrm{e}^{-}
$$

Overcharge at negative electrodes:

$$
\mathrm{O}_{2}+2 \mathrm{H}_{2} \mathrm{O}+4 \mathrm{e}^{-} \longrightarrow 4 \mathrm{OH}^{-}
$$

Side reactions also compete with cell reactions when the operation falls into overdischarge conditions at low capacity levels and are simply described as follows:

Overdischarge at positive electrodes:

$$
2 \mathrm{H}_{2} \mathrm{O}+2 \mathrm{e}^{-} \longrightarrow \mathrm{H}_{2}+2 \mathrm{OH}^{-}
$$

Overdischarge at negative electrodes:

$$
\mathrm{H}_{2}+2 \mathrm{OH}^{-} \longrightarrow 2 \mathrm{H}_{2} \mathrm{O}+2 \mathrm{e}^{-}
$$

Hydrogen transfers from the positive electrode to the negative electrode through the separators with unsaturated electrolyte. Side reactions consume the charge energy without changing electrolyte and electrodes under overcharge and overdischarge conditions. In this way, the $\mathrm{Ni}-\mathrm{MH}$ cells are balanced but cell energy efficiency drops to a lower level. However, it is preferred to avoid these overcharge and overdischarge operating windows because the oxidation reactions are harmful to the battery material durability and shorten the cell operating lifetime. Nelson pointed out that the realistic operation window for hybrid driving duty cycle of HEVs was from $30 \%$ SoC to $70 \%$ SoC [41]. When studying the battery mechanism and capacity decay, this work chooses more tests for the impedance measured at the operating window between $30 \%$ and $70 \%$ SoC, equivalent to the same values of RoC.

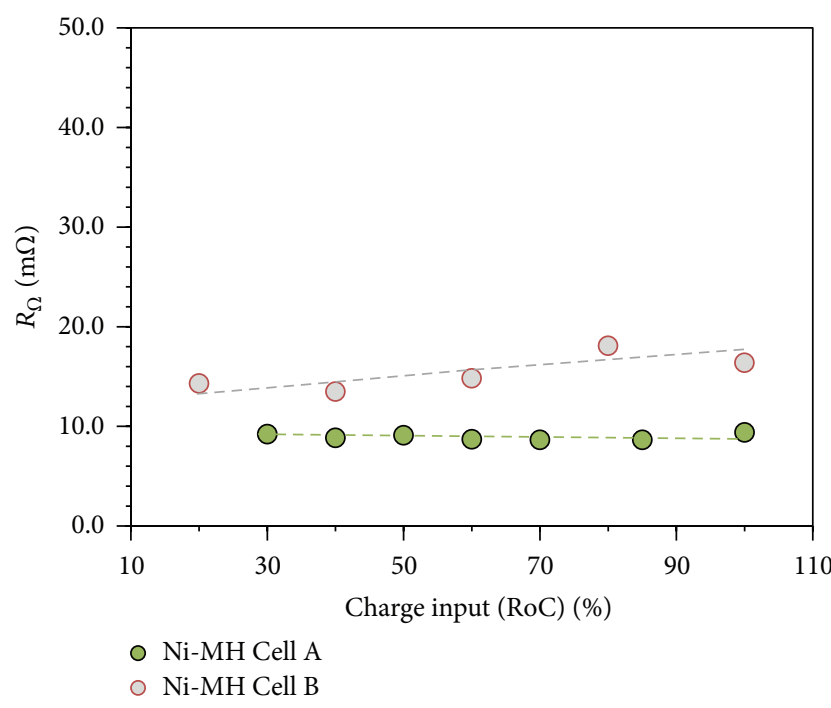

Figure 8: Ohmic resistance $\left(R_{\Omega}\right)$ of the Ni-MH Cell A and Cell B at different RoC levels. Values are calculated from the equivalent circuit simulation.

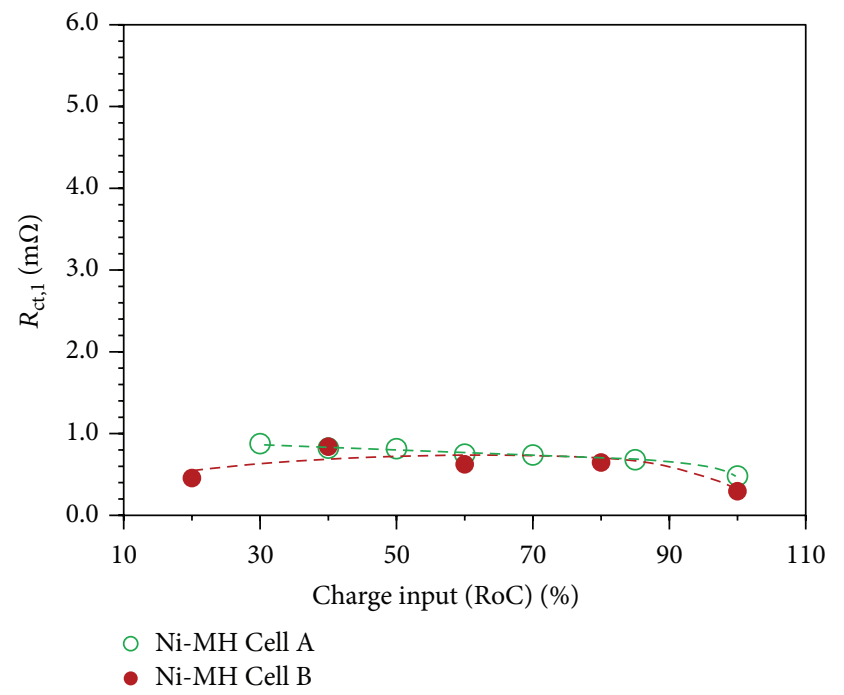

FIGURE 9: Charge transfer resistance contributed by HOR process on the negative electrodes of the Ni-MH Cell A and Cell B at different RoC levels. Values are calculated from the equivalent circuit simulation.

The change of ohmic resistance and charge transfer resistance with charge input levels is shown in Figures 8-10. The resistances of the Ni-MH Cell A and Cell B contributed by the same processes are plotted on the same figure for comparison. The ohmic resistance $R_{\Omega}$ of Cell A stays at a lower and more stable level than Cell B (Figure 8). Between the capacity levels from $20 \%$ to $100 \%$ RoC, the value of $R_{\Omega}$ of Cell B slightly increases with increasing the charge input level likely due to temporary water formation inside the positive electrodes. This potentially results in the changes of local electrolyte concentration and the battery equivalent series resistance $R_{\Omega}$. However, this expected variation is not obviously shown in the Ni-MH Cell A. More concentrated 


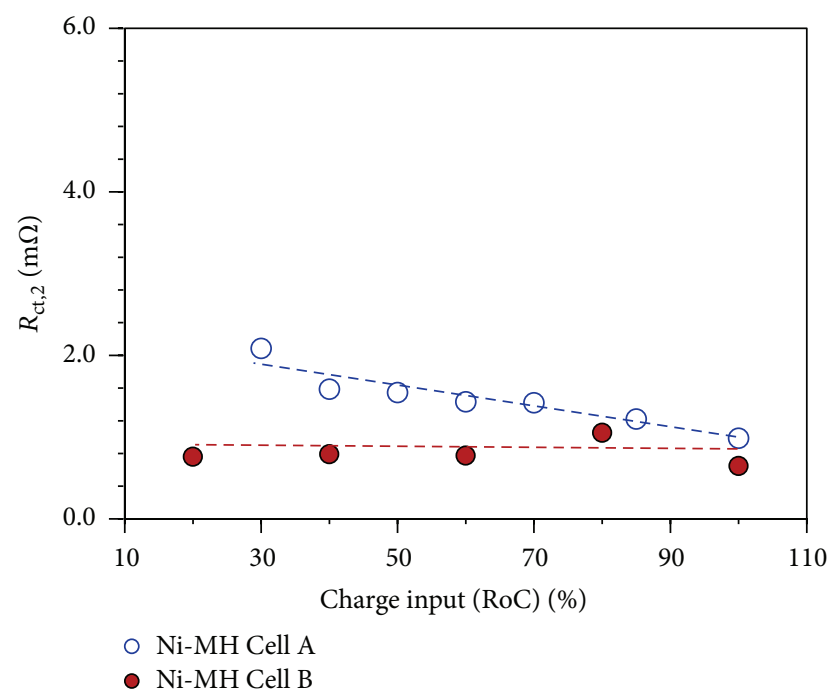

FIgURE 10: Charge transfer resistance contributed by $\mathrm{NiOOH}$ reduction process on the positive electrodes of the Ni-MH Cell A and Cell B at different RoC levels. Values are calculated from the equivalent circuit simulation.

$\mathrm{KOH}$ electrolyte likely contributes to this lower equivalent series resistance $R_{\Omega}$ for Cell A. The status of electrolyte and any other auxiliary components such as electrode material status for hydrogen storage capability also likely contribute to the value change of $R_{\Omega}$ parameter.

The charge transfer resistance contributed by the HOR process on negative electrodes $\left(R_{\mathrm{ct}, 1}\right)$ is plotted against the charge input levels as shown in Figure 9. The cell parameter of $R_{\mathrm{ct}, 1}$ is relatively stable with increasing charge input levels. $R_{\mathrm{ct}, 1}$ of both cells stay at a similar value, which means the electrode kinetics of HOR process on negative electrodes of both cells are equivalent to each other. Although the cell capacities of two cells are different after aging processes, the capacity of negative electrodes is designed at a sufficient level for cell protection. The reduction of cell capacity available is not contributed by the negative electrodes due to a relative stable charge transfer resistance showing the identical negative HOR kinetics.

The Ni-MH cell capacity available is dominated by the amount of capacity at the positive electrode. A visible difference exists between the charge transfer resistances contributed by the positive electrodes $\left(R_{\mathrm{ct}, 2}\right)$ of two Ni$\mathrm{MH}$ cells at different state-of-health levels after years of providing electrical power services through numerous charge and discharge cycles (Figure 10). The Ni-MH Cell B has a relatively more stable $R_{\mathrm{ct}, 2}$ in comparison with that of Cell A, because more active materials available for cell discharge are kept at the positive electrode of Cell B, corresponding to faster kinetics and higher electrode capacity. The more cell capacity available for Cell $\mathrm{B}$ can be reflected by smaller charge transfer resistance at its positive electrode $\left(R_{\mathrm{ct}, 2}\right)$. As a result of experimental measurement, the cell capacity of the $\mathrm{Ni}-\mathrm{MH}$ Cell A after aging process is measured at about $3702 \mathrm{mAh}$, much smaller than the amount of $4362 \mathrm{mAh}$ capacity for Cell B. The positive electrode of Cell A is more degraded compared to Cell B, likely due to limitation of insufficient amount of aqueous $\mathrm{KOH}$ supply, that is, starved electrolyte for the electrochemical reaction of active materials inside the battery. Additionally, the product of $\mathrm{Ni}(\mathrm{OH})_{2}$ at a low level of SoC is estimated to have more impeding effects on electrode kinetic process for energy conversion and delivery (see (14)). Thus, the value of $R_{\mathrm{ct}, 2}$ of the Ni-MH Cell A presents a slightly more increase with decreasing the charge input level (RoC) as expected. The discrimination and interpretation of impedance spectra illustrate that the impedance difference between the Ni-MH cells at different health status resulted firstly from the difference of ohmic resistances and secondly from the active material difference available for $\mathrm{NiOOH}$ reduction reactions on the positive electrodes inside the $\mathrm{Ni}$ $\mathrm{MH}$ cells.

\section{Conclusion}

In this work, measurement using electrochemical impedance spectroscopy (EIS), simulation through an improved equivalent circuit model (ECM), and energy dispersive X-ray spectroscopy (EDX) were applied together to characterize $\mathrm{Ni}-\mathrm{MH}$ rechargeable batteries via an improved equivalent circuit model to examine and analyze chemical reaction mechanisms in the Ni-MH cells. The cell performance degraded due to altered load conditions and various power cycle services. A nonideal equivalent circuit model was derived to simulate impedance spectra measured from both cells at different capacity levels. The significant performance differences were observed from their impedance spectra and equivalent circuit simulation after the cell-aging process. The simulation through the equivalent circuit model broke down the total cell impedance into several parts, corresponding to the real physical elements and chemical reaction steps. Based on the analysis of battery chemistry, the simulation results are interpreted as the ohmic resistance, the impedance of electron transfer process of hydrogen oxidation reaction (HOR) on the negative electrode, the impedance of charge transfer process of $\mathrm{NiOOH}$ reduction process on the positive electrode, and the impedance of solid-state diffusion process on the positive electrode.

The Ni-MH cells studied in this work were at different health status. Their impedance spectra were measured at different charge input levels during discharging process. The ohmic resistance of the $\mathrm{Ni}-\mathrm{MH}$ Cell A stayed at a slightly lower and more stable level. It is likely contributed by more concentrated $\mathrm{KOH}$ electrolyte. The activation resistances on the negative $\mathrm{MH}$ electrodes of both $\mathrm{Ni}-\mathrm{MH}$ cells are basically identical in spite of the amount of charge input increase for the battery. The Ni-MH Cell A had more capacity degradation than that of Cell $\mathrm{B}$, prominently reflected by the activation resistance of the positive electrode inside the cell structure. This work reveals that the impedance tool combined with equivalent circuit simulation is an effective technique to study the effect of the capacity degradation on the battery energy storage and perform battery diagnostics through the electrode reactions and mechanism analysis. It is valuable for further understanding of the Ni-MH power system failure after the battery years of service at different loads, power 
levels, and ambient temperature conditions, highly beneficial to the extensive product improvement, enhancement of battery management systems, and charging infrastructures for better energy harvest on-board with extended service-life cycles.

\section{Conflict of Interests}

The authors declare that there is no conflict of interests regarding the publication of this paper.

\section{Acknowledgments}

This work was performed under a US Army contract at Auburn University (W56HZV-05-C0686) administered through TARDEC. The authors would like to thank Mr. Dwight Cahela, Mrs. Kimberly Dennis, and all CM3 group members for their assistance and contribution to this work.

\section{References}

[1] C. Lambertson, "Lithium-ion battery simulation for greener ford vehicles," COMSOL News, Comsol, Inc., Burlington, Mass, USA, pp. 8-11, 2011.

[2] A. S. Bandarenka, "Exploring the interfaces between metal electrodes and aqueous electrolytes with electrochemical impedance spectroscopy," Analyst, vol. 138, no. 19, pp. 55405554, 2013.

[3] A. K. Arof, S. Amirudin, S. Z. Yusof, and I. M. Noor, "A method based on impedance spectroscopy to determine transport properties of polymer electrolytes," Physical Chemistry Chemical Physics, vol. 16, no. 5, pp. 1856-1867, 2014.

[4] J. F. Rubinson and Y. P. Kayinamura, "Charge transport in conducting polymers: insights from impedance spectroscopy," Chemical Society Reviews, vol. 38, no. 12, pp. 3339-3347, 2009.

[5] C. Z. Yang, M. Zhou, and Q. Xu, “Three-dimensional ordered macroporous $\mathrm{MnO}_{2}$ /carbon nanocomposites as highperformance electrodes for asymmetric supercapacitors," Physical Chemistry Chemical Physics, vol. 15, no. 45, pp. 19730-19740, 2013.

[6] I. Mora-Seró, G. Garcia-Belmonte, P. P. Boix, M. A. Vázquez, and J. Bisquert, "Impedance spectroscopy characterisation of highly efficient silicon solar cells under different light illumination intensities," Energy \& Environmental Science, vol. 2, no. 6, pp. 678-686, 2009.

[7] R. U. Payne, Y. Zhu, W. H. Zhu, M. S. Timper, S. Elangovan, and B. J. Tatarchuk, "Diffusion and gas conversion analysis of solid oxide fuel cells at loads via AC impedance," International Journal of Electrochemistry, vol. 2011, Article ID 465452, 11 pages, 2011.

[8] Y. Zhu, W. H. Zhu, and B. J. Tatarchuk, "Performance comparison between high temperature and traditional proton exchange membrane fuel cell stacks using electrochemical impedance spectroscopy," Journal of Power Sources, vol. 256, pp. 250-257, 2014.

[9] Y. F. Liu, H. G. Pan, M. X. Gao, and Q. D. Wang, "Advanced hydrogen storage alloys for $\mathrm{Ni} / \mathrm{MH}$ rechargeable batteries," Journal of Materials Chemistry, vol. 21, no. 13, pp. 4743-4755, 2011.
[10] M. R. Palacín, "Recent advances in rechargeable battery materials: a chemist's perspective," Chemical Society Reviews, vol. 38, no. 9, pp. 2565-2575, 2009.

[11] J. G. Zhu, Z. C. Sun, X. Z. Wei, and H. F. Dai, "A new electrochemical impedance spectroscopy model of a highpower lithium-ion battery," RSC Advances, vol. 4, no. 57, pp. 29988-29998, 2014.

[12] W. H. Zhu, Y. Zhu, and B. J. Tatarchuk, "A simplified equivalent circuit model for simulation of $\mathrm{Pb}$-acid batteries at load for energy storage application," Energy Conversion and Management, vol. 52, no. 8-9, pp. 2794-2799, 2011.

[13] D. D. Macdonald, B. G. Pound, and S. J. Lenhart, "The application of electrochemical impedance spectroscopy for characterizing the degradation of $\mathrm{Ni}(\mathrm{OH})_{2} / \mathrm{NiOOH}$ electrodes," Journal of Power Sources, vol. 29, no. 3-4, pp. 477-502, 1990.

[14] A. H. Zimmerman and P. K. Effa, "Discharge kinetics of the nickel electrode," Journal of the Electrochemical Society, vol. 131, no. 4, pp. 709-713, 1984.

[15] Y. W. Li, J. H. Yao, Y. X. Zhu, Z. G. Zou, and H. B. Wang, "Synthesis and electrochemical performance of mixed phase $\alpha / \beta$ nickel hydroxide," Journal of Power Sources, vol. 203, pp. 177-183, 2012.

[16] M. Ortiz, D. Becker, G. Garaventta, A. Visintin, E. B. Castro, and S. G. Real, "Dynamic monitoring of structural changes in nickel hydroxide electrodes during discharge in batteries," Electrochimica Acta, vol. 56, no. 23, pp. 7946-7954, 2011.

[17] N. Kuriyama, T. Sakai, H. Miyamura, I. Uehara, H. Ishikawa, and T. Iwasaki, "Electrochemical impedance and deterioration behavior of metal hydride electrodes," Journal of Alloys and Compounds, vol. 202, no. 1-2, pp. 183-197, 1993.

[18] R. M. Humana, J. E. Thomas, F. Ruiz, S. G. Real, E. B. Castro, and A. Visintin, "Electrochemical behavior of metal hydride electrode with different particle size," International Journal of Hydrogen Energy, vol. 37, no. 19, pp. 14966-14971, 2012.

[19] F. C. Ruiz, P. S. Martínez, E. B. Castro, R. Humana, H. A. Peretti, and A. Visintin, "Effect of electrolyte concentration on the electrochemical properties of an $\mathrm{AB}_{5}$-type alloy for $\mathrm{Ni} / \mathrm{MH}$ batteries," International Journal of Hydrogen Energy, vol. 38, no. 1, pp. 240-245, 2013.

[20] M. Tliha, S. Boussami, H. Mathlouthi, J. Lamloumi, and A. Percheron-Guégan, "Electrochemical characteristics of AB5type hydrogen storage alloys," Journal of Alloys and Compounds, vol. 506, no. 2, pp. 559-564, 2010.

[21] F. Huet, "A review of impedance measurements for determination of the state-of-charge or state-of-health of secondary batteries," Journal of Power Sources, vol. 70, no. 1, pp. 59-69, 1998.

[22] K. Bundy, M. Karlsson, G. Lindbergh, and A. Lundqvist, "An electrochemical impedance spectroscopy method for prediction of the state of charge of a nickel-metal hydride battery at open circuit and during discharge," Journal of Power Sources, vol. 72, no. 2, pp. 118-125, 1998.

[23] A. Hammouche, E. Karden, and R. W. De Doncker, "Monitoring state-of-charge of Ni-MH and Ni-Cd batteries using impedance spectroscopy," Journal of Power Sources, vol. 127, no. 1-2, pp. 105111, 2004.

[24] M. Thele, O. Bohlen, D. U. Sauer, and E. Karden, "Development of a voltage-behavior model for $\mathrm{NiMH}$ batteries using an impedance-based modeling concept," Journal of Power Sources, vol. 175, no. 1, pp. 635-643, 2008.

[25] E. B. Castro, D. J. Cuscueta, R. H. Milocco, A. A. Ghilarducci, and H. R. Salva, "An EIS based study of a Ni-MH battery 
prototype. Modeling and identification analysis," International Journal of Hydrogen Energy, vol. 35, no. 11, pp. 5991-5998, 2010.

[26] P. Slepski, K. Darowicki, E. Janicka, and A. Sierczynska, "Application of electrochemical impedance spectroscopy to monitoring discharging process of nickel/metal hydride battery," Journal of Power Sources, vol. 241, pp. 121-126, 2013.

[27] D. Linden and T. B. Reddy, Handbook of Batteries, McGraw-Hill, 2002.

[28] W. H. Zhu, Y. Zhu, Z. Davis, and B. J. Tatarchuk, "Energy efficiency and capacity retention of Ni-MH batteries for storage applications," Applied Energy, vol. 106, pp. 307-313, 2013.

[29] P. T. Wojcik, P. Agarwal, and M. E. Orazem, "A method for maintaining a constant potential variation during galvanostatic regulation of electrochemical impedance measurements," Electrochimica Acta, vol. 41, no. 7-8, pp. 977-983, 1996.

[30] Y. Zhu, W. H. Zhu, and B. J. Tatarchuk, "In-situ dynamic characterization of energy storage and conversion systems," in Energy Storage - Technologies and Applications, A. F. Zobaa, Ed., chapter 10, pp. 239-270, InTech, Rijeka, Croatia, 2013.

[31] M. A. Fetcenko, S. R. Ovshinsky, B. Reichman et al., "Recent advances in NiMH battery technology," Journal of Power Sources, vol. 165, no. 2, pp. 544-551, 2007.

[32] S. R. Ovshinsky, M. A. Fetcenko, and J. Ross, "A nickel metal hydride battery for electric vehicles," Science, vol. 260, no. 5105, pp. 176-181, 1993.

[33] E. Barsoukov and J. R. Macdonald, Eds., Impedance Spectroscopy: Theory, Experiment, and Applications, Wiley-Interscience, 2nd edition, 2005.

[34] A. Lasia, "Modeling of impedance of porous electrodes," in Modeling and Numerical Simulations, M. Schlesinger, Ed., vol. 43 of Modern Aspects of Electrochemistry, chapter 3, pp. 67-137, Springer, New York, NY, USA, 2009.

[35] K. A. Murugesamoorthi, S. Srinivasan, and A. J. Appleby, "AC impedance studies on nickel oxide electrodes to determine selfdischarge characteristics of $\mathrm{Ni}-\mathrm{H}_{2}$ batteries," Journal of Applied Electrochemistry, vol. 21, no. 2, pp. 95-98, 1991.

[36] L. O. Valoen, A. Lasia, J. O. Jensen, and R. Tunold, "The electrochemical impedance of metal hydride electrodes," Electrochimica Acta, vol. 47, no. 18, pp. 2871-2884, 2002.

[37] E. Karden, S. Buller, and R. W. De Doncker, "A method for measurement and interpretation of impedance spectra for industrial batteries," Journal of Power Sources, vol. 85, no. 1, pp. 72-78, 2000.

[38] W. L. Zhang, M. P. S. Kumar, S. Srinivasan, and H. J. Ploehn, "AC impedance studies on metal hydride electrodes," Journal of the Electrochemical Society, vol. 142, no. 9, pp. 2935-2943, 1995.

[39] M. Vitanen, "A mathematical model for metal hydride electrodes," Journal of the Electrochemical Society, vol. 140, no. 4, pp. 936-942, 1993.

[40] H. Wenzl, "BATTERIES: capacity," in Encyclopedia of Electrochemical Power Sources, C. K. Dyer, P. T. Moseley, Z. Ogumi, D. A. J. Rand, B. Scrosati, and J. Garche, Eds., vol. 1, pp. 395-400, Elsevier B.V., Madrid, Spain, 2009.

[41] R. F. Nelson, "Power requirements for batteries in hybrid electric vehicles," Journal of Power Sources, vol. 91, no. 1, pp. 226, 2000. 

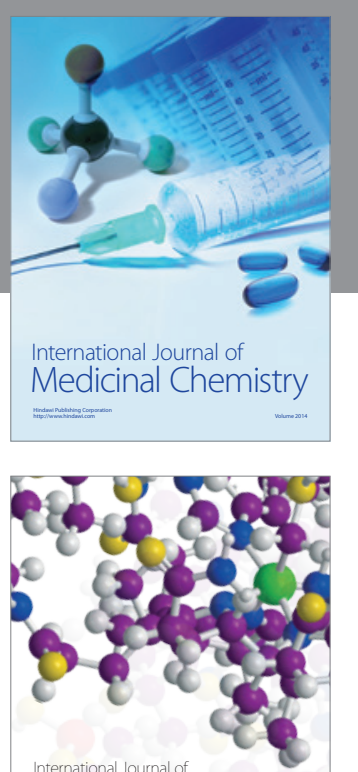

Carbohydrate Chemistry

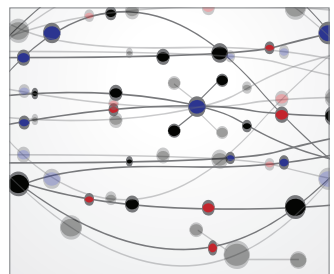

The Scientific World Journal
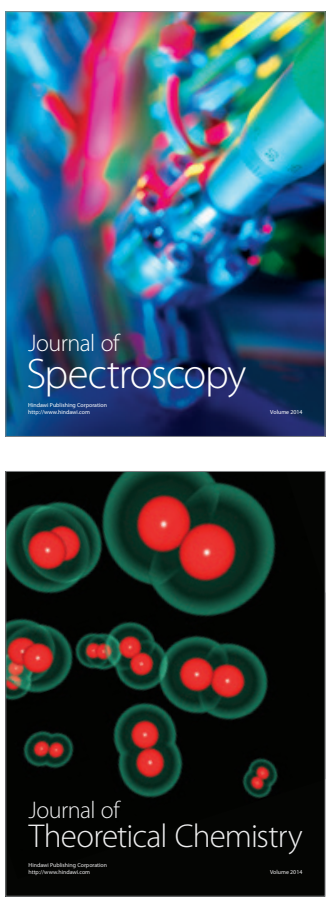
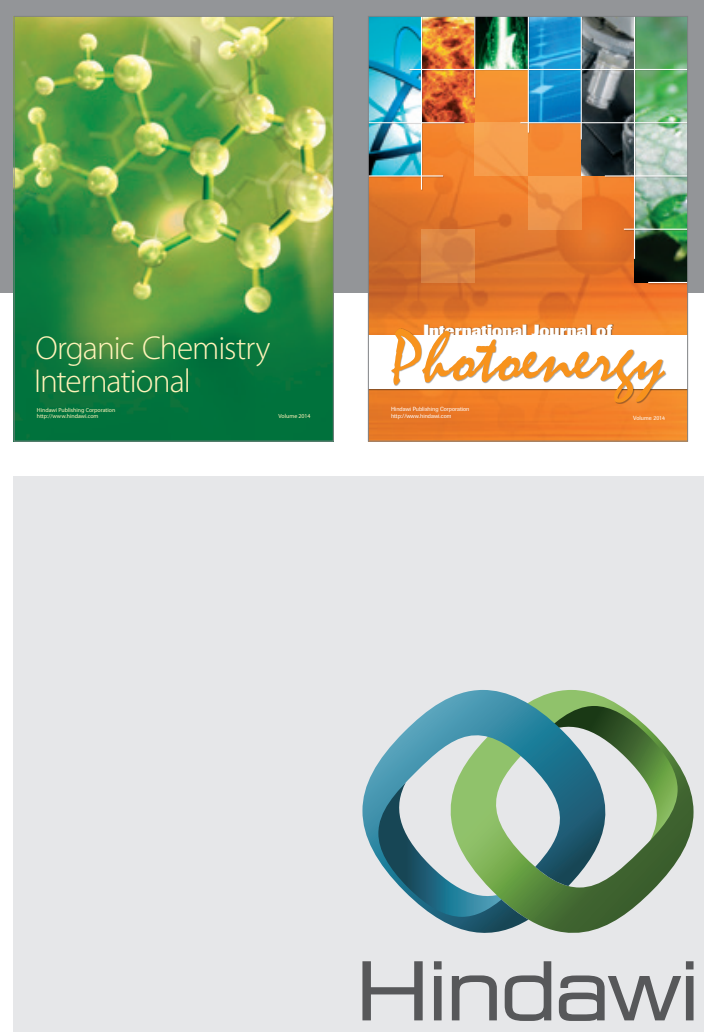

Submit your manuscripts at

http://www.hindawi.com

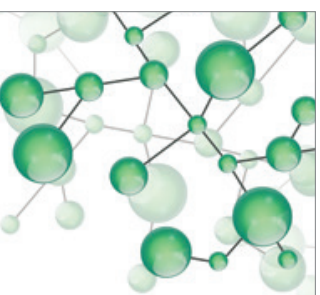

International Journal of

Inorganic Chemistry

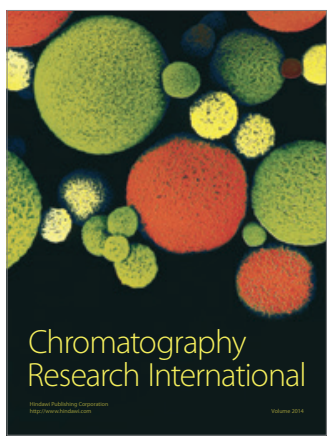

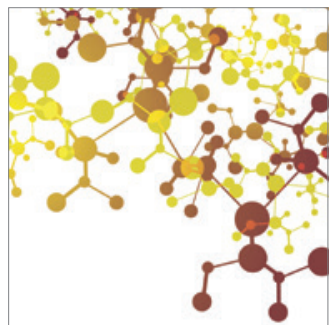

Applied Chemistry
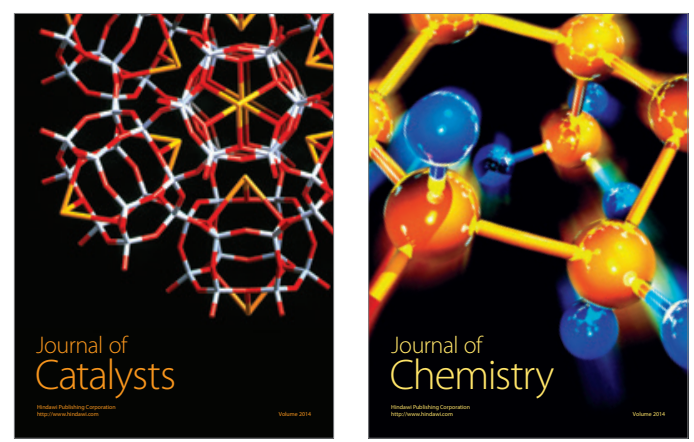
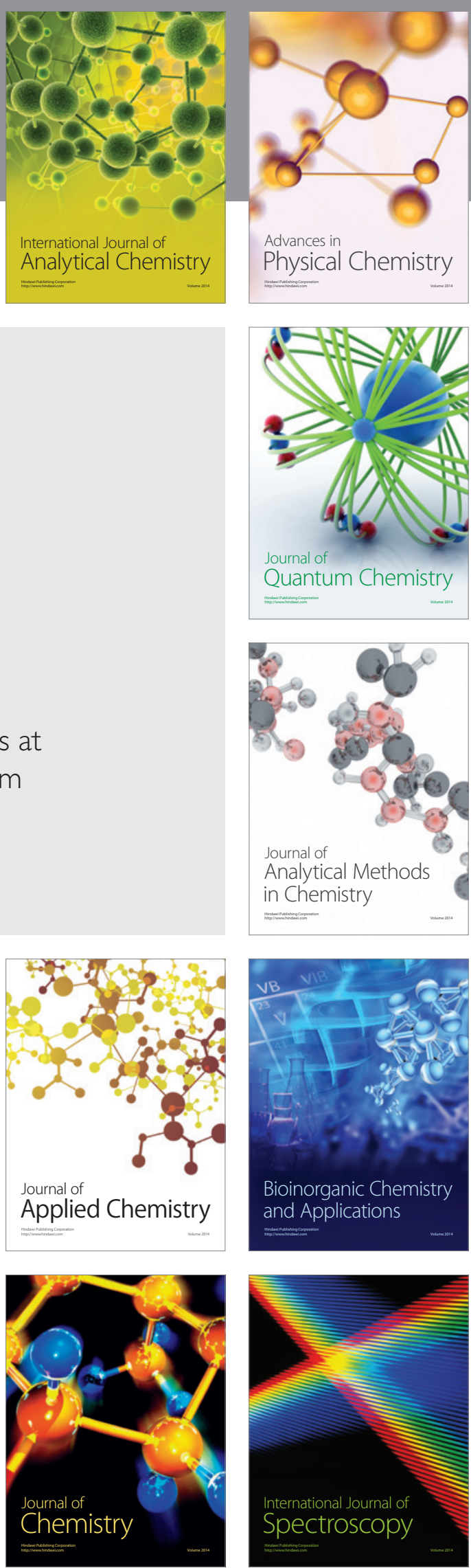